\title{
Lead-free piezoelectric transducers for microelectronic wirebonding applications
}

\author{
K.W. Kwok, T. Lee, S.H. Choy and H.L.W. Chan \\ Department of Applied Physics, The Hong Kong Polytechnic University \\ Kowloon, Hong Kong, China
}

\section{Introduction}

Lead-free piezoelectric ceramics have been extensively studied recently for replacing the widely used lead-based piezoelectric materials for environmental protection reasons. Among various candidates, potassium sodium niobate-based and bismuth titanate-based ceramics are the two most promising alternatives. In this chapter, the use of $\left(\mathrm{K}_{0.475} \mathrm{Na}_{0.475} \mathrm{Li}_{0.05}\right)\left(\mathrm{Nb}_{0.92} \mathrm{Ta}_{0.05} \mathrm{Sb}_{0.03}\right) \mathrm{O}_{3}$ added with $0.4 w t \% \quad \mathrm{CeO}_{2}$ and $0.4 w t \% \quad \mathrm{MnO}_{2}$ (abbreviated KNLNTS) and $0.885\left(\mathrm{Bi}_{0.5} \mathrm{Na}_{0.5}\right) \mathrm{TiO}_{3}-0.05\left(\mathrm{Bi}_{0.5} \mathrm{~K}_{0.5}\right) \mathrm{TiO}_{3}-0.015\left(\mathrm{Bi}_{0.5} \mathrm{Li}_{0.5}\right) \mathrm{TiO}_{3}-$ $0.05 \mathrm{BaTiO}_{3}$ (abbreviated as $\mathrm{BNKLBT}$ ) lead-free piezoelectric ceramics as the driving elements of ultrasonic wirebonding transducers is reported. The fabrication and characterization of the ceramics, in the form of ring, and the wirebonding transducers are presented. The ceramic rings are fastened and pre-stressed through a pair of titanium alloy plates in the transducers. The vibration characteristics of the ceramic rings and the transducers are analyzed using a finite-element method (FEM). On the basis of the simulation results, the dimensions of the rings and the titanium alloy plates are determined. The lead-free transducers, operating at a frequency of $\sim 65 \mathrm{kHz}$, exhibit comparable voltage rise and fall times as the commercial lead zirconate titanate (PZT) transducers. Because of the better matching of the acoustic impedances between the ceramic and titanium alloy, an effective transfer of vibration energy is achieved in the transducers, leading to a large axial vibration $(\sim 1.7 \mu \mathrm{m}$ at $0.1 \mathrm{~W})$. Moreover, the lead-free transducers exhibit a small lateral vibration $(0.05 \mu \mathrm{m}$ at $0.1 \mathrm{~W})$, which is essential for producing a small or narrow bond. The transducers have successfully bonded the aluminum wire on the standard die and gold-plated PCB. The bonds are of good quality, having a smaller deformation ratio (as compared to the commercial PZT transducer) and high bond strength (exceeding the industrial requirement). These clearly show that the lead-free piezoelectric ceramics are promising candidates for replacing the lead-based ceramics as a driving element in the future generation of wire bonders.

\section{Lead-free Piezoelectric Ceramics}

Lead-based piezoelectric ceramics, represented by $\mathrm{Pb}(\mathrm{Zr}, \mathrm{Ti}) \mathrm{O}_{3}$ (PZT) and PZT-based multicomponent materials, have been widely used for piezoelectric actuators, sensors, transducers as well as microelectronic devices due to their excellent piezoelectric properties. 
However, they contain a large amount of lead (more than $60 \mathrm{wt} \%$ ). As lead is highly toxic and will vaporize during processing of the ceramics, there is a rising concern about manufacture as well as disposal of products containing PZT. To date, the lead-free piezoelectric ceramics that have been extensively studied belong to the bismuth-layered and perovsike structures. Bismuth-layered ceramics are featured with low permittivity and high Curie temperature, and hence they have been widely studied for high-temperature sensor applications. For perovskite-type structures, $\mathrm{K}_{0.5} \mathrm{Na}_{0.5} \mathrm{NbO}_{3}$-based and $\mathrm{Bi}_{0.5} \mathrm{Na}_{0.5} \mathrm{TiO}_{3}$-based piezoelectric ceramics have attracted considerable attention because of their good piezoelectric properties, and have been considered the most promising alternatives to leadbased piezoelectric ceramics.

$\mathrm{K}_{0.5} \mathrm{Na}_{0.5} \mathrm{NbO}_{3}$ (abbreviated as $\mathrm{KNN}$ ) is a solid solution of ferroelectric $\mathrm{KNbO}_{3}$ and antiferroelectric $\mathrm{NaNbO}_{3}$, with the composition $\mathrm{K} / \mathrm{Na}=50 / 50$ close to the morphotropic phase boundary. It has a high Curie temperature (above $400^{\circ} \mathrm{C}$ ), good ferroelectric properties, and large electromechanical coupling coefficients. A dense and well-sintered KNN ceramic (e.g., prepared by the hot-pressing technique) possesses a high density $\left(\rho=4.46 \mathrm{~g} / \mathrm{cm}^{3}\right)$ and good piezoelectric properties (piezoelectric coefficient $\mathrm{d}_{33}=160 \mathrm{pC} / \mathrm{N}$ and planar-mode electromechanical coupling coefficient $k_{p}=0.45$ ) (Jaeger \& Egerton, 1962). However, because of the high volatility of alkaline elements at high temperatures, it is very difficult to obtain dense and well-sintered KNN ceramics using a conventional sintering process, and the ceramics usually exhibit worse piezoelectric properties $\left(\mathrm{d}_{33}=80 \mathrm{pC} / \mathrm{N}, \mathrm{k}_{\mathrm{p}}=0.36\right)$ and low density $(\rho=$ $\left.4.25 \mathrm{~g} / \mathrm{cm}^{3}\right)$. A number of studies have been carried out to improve the sinterability and properties of KNN ceramics; these include the formation of solid solutions of KNN with other $\mathrm{ABO}_{3}$-type ferroelectrics or nonferroelectrics, e.g., $\mathrm{LiNbO}_{3}$ (Guo et al., 2004), $\mathrm{Bi}_{0.5} \mathrm{Na}_{0.5} \mathrm{TiO}_{3}$ (Zuo et al., 2007), $\mathrm{BaTiO}_{3}$ (Ahn et al., 2005), $\mathrm{Ba}\left(\mathrm{Ti}_{0.95} \mathrm{Zr}_{0.05}\right) \mathrm{O}_{3}$ (Lin et al., 2007a), $\mathrm{SrTiO}_{3}$ (Wang et al., 2005), $\mathrm{LiTaO}_{3}$ (Guo et al., 2005), and $\mathrm{LiSbO}_{3}$ (Lin et al., 2007b), the substitutions of analogous ions (e.g., $\mathrm{Li}^{+}, \mathrm{Sb}^{5+}$ and $\mathrm{Ta}^{5+}$ ) for the $\mathrm{A}$-site $\mathrm{K}^{+}$and $\mathrm{Na}^{+}$or the $\mathrm{B}$-site $\mathrm{Nb}^{5+}$ ions (Saito et al., 2004; Lin et al., 2008a), and the use of sintering aids, e.g., $\mathrm{CuO}$ (Lin et al., 2008b) and $\mathrm{K}_{5.4} \mathrm{Cu}_{1.3} \mathrm{Ta}_{10} \mathrm{O}_{29}$ (Matsubara et al., 2005). Among various KNN-based ceramics, KNN ceramics co-modified with $\mathrm{Li}$ and Ta have been widely studied, and good piezoelectric properties have been reported for several compositions, e.g., $\left(\mathrm{K}_{0.5} \mathrm{Na}_{0.5}\right)_{0.96} \mathrm{Li}_{0.04}\left(\mathrm{Nb}_{0.90} \mathrm{Ta}_{0.10}\right)_{3}$ and $\left(\mathrm{K}_{0.5} \mathrm{Na}_{0.5}\right)_{0.97} \mathrm{Li}_{0.03}\left(\mathrm{Nb}_{0.80} \mathrm{Ta}_{0.20}\right) \mathrm{O}_{3}$ (Saito et al., 2004). Recently, our studies have shown that $\mathrm{CeO}_{2}$ and $\mathrm{MnO}_{2}$ are effective in improving the piezoelectric properties of the $\left(\mathrm{K}_{0.475} \mathrm{Na}_{0.475} \mathrm{Li}_{0.05}\right)\left(\mathrm{Nb}_{0.92} \mathrm{Ta}_{0.05} \mathrm{Sb}_{0.03}\right) \mathrm{O}_{3}$ ceramic (Lee et al., 2008; Lee, 2008). For the ceramic added with $0.4 \mathrm{wt} \% \mathrm{CeO}_{2}$ and $0.4 \mathrm{wt} \% \mathrm{MnO}_{2}$, the piezoelectric and dielectric properties become optimum, having a $\mathrm{d}_{33}$ of $200 \mathrm{pC} / \mathrm{N}$, a relative permittivity $\varepsilon_{\mathrm{r}}$ of 1150 , a loss tangent $\tan \delta$ of $1.9 \%$, a $\mathrm{k}_{\mathrm{p}}$ of 0.43 and a mechanical quality factor $\mathrm{Q}_{\mathrm{m}}$ of 80 .

$\mathrm{Bi}_{0.5} \mathrm{Na}_{0.5} \mathrm{TiO}_{3}$ (abbreviated as BNT) is a perovskite-structured ferroelectric having $\mathrm{Bi}^{3+}$ and $\mathrm{Na}^{+}$complex on the A site of $\mathrm{ABO}_{3}$-type compounds with a rhombohedral symmetry. It has a high Curie temperature $\left(\mathrm{T}_{\mathrm{c}}=320^{\circ} \mathrm{C}\right)$ and strong ferroelectricity, exhibiting a relatively large remanent polarization $\left(\mathrm{P}_{\mathrm{r}}=38 \mu \mathrm{C} / \mathrm{cm}^{2}\right)$ and a high coercive field $\left(\mathrm{E}_{\mathrm{c}}=73 \mathrm{kV} / \mathrm{cm}\right)$ at room temperature (Takennaka et al., 1991). Since its discovery by Smolenskii et al. (1961), many studies have focused on this lead-free ferroelectric ceramic. However, because of its high conductivity and coercive field, the poling of the ceramic is difficult and inefficient. As a result, BNT ceramics usually exhibit much weaker piezoelectric properties $\left(d_{33}=73-80\right.$ pC/N) as compared with $\mathrm{Pb}\left(\mathrm{Zr}_{0.52} \mathrm{Ti}_{0.48}\right) \mathrm{O}_{3}$ ceramics $\left(\mathrm{d}_{33}=223 \mathrm{pC} / \mathrm{N}\right)$ (Yoshii et al., 2006). In order to improve the poling process and enhance the piezoelectric properties, a number of 
studies have been carried out; these include the formation of solid solutions of BNT with other $\mathrm{ABO}_{3}$-type ferroelectrics or nonferroelectrics, e.g. BNT-BaTiO 3 (Takennaka et al., 1991; $\mathrm{Xu}$ et al., 2008), BNT-Bi $0_{0.5} \mathrm{~K}_{0.5} \mathrm{TiO}_{3}$ (Yoshii et al., 2006), BNT-KNbO 3 (Fan et al., 2008), BNT$\mathrm{BiAlO}_{3}(\mathrm{Yu} \& \mathrm{Ye}, 2008$ ), BNT-SrTiO 3 (Hiruma et al., 2008), BNT-KNN (Kounga et al., 2008), BNT- $\mathrm{Bi}_{0.5} \mathrm{~K}_{0.5} \mathrm{TiO}_{3}-\mathrm{KNbO}_{3}$ (Fan et al., 2007), BNT-Bi ${ }_{0.5} \mathrm{~K}_{0.5} \mathrm{TiO}_{3}-\mathrm{BiFeO}_{3}$ (Zhou et al., 2009) and BNT- $\mathrm{Bi}_{0.5} \mathrm{~K}_{0.5} \mathrm{TiO}_{3}-\mathrm{BaTiO}_{3}$ (Nagata et al., 2003; Wang et al., 2004a; Li et al., 2005; Makiuchi et al., 2005), the substitutions of analogous ions for the A-site $\left(\mathrm{Bi}_{0.5} \mathrm{Na}_{0.5}\right)^{+}$or $\mathrm{B}$-site $\mathrm{Ti}^{4+}$ ions, e.g. $\left(\mathrm{Bi}_{1 / 2} \mathrm{Na}_{1 / 2}\right) \mathrm{Ti}_{1-\mathrm{x}}\left(\mathrm{Zn}_{1 / 3} \mathrm{Nb}_{2 / 3}\right) \times \mathrm{O}_{3}$ (Zhou \& Liu, 2008), (Bi $\left.\mathrm{ZNNa}_{0.5}\right)_{0.94} \mathrm{Ba}_{0.06} \mathrm{Zr}_{\mathrm{y}} \mathrm{Ti}_{1-\mathrm{y}} \mathrm{O}_{3}$ (Yao et al., 2007) and $\left(\mathrm{Bi}_{0.5} \mathrm{Na}_{0.5}\right)_{1-1.5 \times} \mathrm{Bi}_{x} \mathrm{TiO}_{3}$ (Wang et al., 2004b), and the doping of metal oxides, e.g. Ta-doped 0.94BNT-0.06BaTiO 3 (Zuo et al., 2008) and $\mathrm{CeO}_{2}$-doped $\mathrm{Bi}_{0.5} \mathrm{Na}_{0.44} \mathrm{~K}_{0.06} \mathrm{TiO}_{3}$ ( $\mathrm{Li}$ et al., 2007). Among various BNT-based ceramics, the ternary systems $\left(\mathrm{Bi}_{0.5} \mathrm{Na}_{0.5}\right) \mathrm{TiO}_{3}-$ $\left(\mathrm{Bi}_{0.5} \mathrm{~K} 0.5\right) \mathrm{TiO}_{3}-\mathrm{BaTiO}_{3}$ have relatively high piezoelectric and good dielectric properties for compositions near the morphotropic phase boundary. Our studies have shown that after the doping of bismuth lithium titanate $\left(\mathrm{Bi}_{0.5} \mathrm{Li}_{0.5}\right) \mathrm{TiO}_{3}$, both the electromechanical coupling factors and mechanical quality factors of the ceramics can be further improved and the dielectric loss can be reduced (Choy et al., 2007).

In the following sections, the preparation and characterization of $\left(\mathrm{K}_{0.475} \mathrm{Na}_{0.475} \mathrm{Li}_{0.05}\right)\left(\mathrm{Nb}_{0.92} \mathrm{Ta}_{0.05} \mathrm{Sb}_{0.03}\right) \mathrm{O}_{3}$ added with 0.4 wt $\% \mathrm{CeO}_{2}$ and $0.4 \mathrm{wt} \% \mathrm{MnO}_{2}$ (abbreviated KNLNTS) and $0.885\left(\mathrm{Bi}_{0.5} \mathrm{Na}_{0.5}\right) \mathrm{TiO}_{3}-0.05\left(\mathrm{Bi}_{0.5} \mathrm{~K}_{0.5}\right) \mathrm{TiO}_{3}-0.015\left(\mathrm{Bi}_{0.5} \mathrm{Li}_{0.5}\right) \mathrm{TiO}_{3^{-}}$ $0.05 \mathrm{BaTiO}_{3}$ (abbreviated as BNKLBT) lead-free piezoelectric ceramics, in the form of ring, will be presented. The ceramic rings will be used, as the driving elements, to fabricate ultrasonic wirebonding transducers.

\subsection{Preparation of Ceramic Rings}

\subsubsection{KNLNTS}

The KNLNTS ceramic rings were prepared by a conventional mixed oxide method using analytical-grad metal oxides or carbonate powders: $\mathrm{Na}_{2} \mathrm{CO}_{3}(99.95 \%), \mathrm{K}_{2} \mathrm{CO}_{3}(99 \%), \mathrm{Li}_{2} \mathrm{CO}_{3}$ (99\%), $\mathrm{Nb}_{2} \mathrm{O}_{5}(99.99 \%), \mathrm{Ta}_{2} \mathrm{O}_{5}(99.99 \%), \mathrm{Sb}_{2} \mathrm{O}_{5}(99 \%), \mathrm{MnO}_{2}$ (99.99\%) and $\mathrm{CeO}_{2}(99.9 \%)$. The powders in the stoichiometric ratio of the composition $\left(\mathrm{K}_{0.475} \mathrm{Na}_{0.475} \mathrm{Li}_{0.05}\right)\left(\mathrm{Nb}_{0.92} \mathrm{Ta}_{0.05} \mathrm{Sb}_{0.03}\right) \mathrm{O}_{3}$ were first dried and mixed thoroughly in ethanol using zirconia balls for $10 \mathrm{~h}$. After the calcination at $900^{\circ} \mathrm{C}$ for $2 \mathrm{~h}, 0.4 \mathrm{wt} \% \mathrm{CeO}_{2}$ and $0.4 \mathrm{wt} \% \mathrm{MnO}_{2}$ were added. The mixture was then ball-milled again for $10 \mathrm{~h}$ and mixed thoroughly with a poly(vinylalcohol) (PVA) binder solution, and then uniaxially pressed into ring samples. The samples were finally sintered at $1140^{\circ} \mathrm{C}$ for $4 \mathrm{~h}$ in air. Silver electrodes were fired on the top and bottom surfaces of the samples. The ceramic samples were poled under a dc field of $4 \mathrm{kV} / \mathrm{mm}$ at $150^{\circ} \mathrm{C}$ in a silicone oil bath for $30 \mathrm{~min}$.

\subsubsection{BNKLBT}

The conventional mixed oxide technique was used to prepare the BNKLBT ceramic rings. Reagent-grade $\mathrm{Bi}_{2} \mathrm{O}_{3}(99.9 \%), \mathrm{Na}_{2} \mathrm{CO}_{3}(99.95 \%), \mathrm{K}_{2} \mathrm{CO}_{3}(99 \%), \mathrm{Li}_{2} \mathrm{CO}_{3}(99+\%), \mathrm{BaCO}_{3}$ and $\mathrm{TiO}_{2}(99.9 \%)$ were used as raw materials. The raw materials were weighed according to the formula $0.885\left(\mathrm{Bi}_{0.5} \mathrm{Na}_{0.5}\right) \mathrm{TiO}_{3}-0.05\left(\mathrm{Bi}_{0.5} \mathrm{~K}_{0.5}\right) \mathrm{TiO}_{3}-0.015\left(\mathrm{Bi}_{0.5} \mathrm{Li}_{0.5}\right) \mathrm{TiO}_{3}-0.05 \mathrm{BaTiO}_{3}$. The powder was ball milled in ethanol using zirconia balls for $10 \mathrm{~h}$. Calcination was conducted at $800^{\circ} \mathrm{C}$ for $2 \mathrm{~h}$. After calcination, the mixture was dried and PVA was added as a binder for granulation. The granulated powders were pressed into rings. The compacted rings were sintered at 
$1170^{\circ} \mathrm{C}$ for $2 \mathrm{~h}$ in air. Silver electrodes were applied on both surfaces of the rings and fired at $650^{\circ} \mathrm{C}$. The samples were poled in silicone oil at room temperature under $4 \mathrm{kV} / \mathrm{mm}$ for $10 \mathrm{~min}$.

\subsection{Material Properties}

The KNLNTS and BNKLBT ceramics have been characterized in detail in our previous works (Lee et al., 2009; Chan et al., 2008). Table 1 lists some of the general material parameters of the ceramics, while the material parameters (with conventional symbols) used for the FEM simulations are summarized in Table 2. The material parameters for the PZT (APC 840) ceramic which is currently used in the commercial wirebonding transducers are also listed in Table 1 for comparison. The ceramic rings prepared in this work were characterized and similar results were obtained. The density $\rho$ of the ceramics was measured using the Archimedes method. The relative permittivity $\varepsilon_{\mathrm{r}}$ and loss tangent $\tan \delta$ were measured using an impedance analyzer (HP 4294A) at $1 \mathrm{kHz}$. The piezoelectric coefficient $\mathrm{d}_{33}$ was measured using a piezo-d33 meter (ZJ-30, China).

\begin{tabular}{|c|c|c|c|}
\hline Material parameters & KNLNTS & BNKLBT & $\begin{array}{c}\text { PZT (APC } \\
840)\end{array}$ \\
\hline Density $\rho\left(\mathrm{kg} / \mathrm{m}^{3}\right)$ & 4600 & 5780 & 7516 \\
\hline$\varepsilon_{\mathrm{r}}($ at $1 \mathrm{kHz})$ & 1150 & 766 & 1112 \\
\hline $\tan \delta(\%)$ & 1.9 & 1.61 & 0.75 \\
\hline $\mathrm{k}_{\mathrm{t}}$ & 0.32 & 0.524 & 0.357 \\
\hline $\mathrm{k}_{\mathrm{p}}$ & 0.43 & 0.328 & 0.59 \\
\hline $\mathrm{k}_{31}$ & 0.26 & 0.188 & 0.32 \\
\hline $\mathrm{d}_{33}(\mathrm{pC} / \mathrm{N})$ & 200 & 163 & 254 \\
\hline $\mathrm{Q}_{\mathrm{m} \text { (radial) }}$ & 80 & 142.1 & 774.5 \\
\hline Poisson's ratio $\sigma$ & 0.39 & 0.278 & 0.395 \\
\hline Young's modulus $\mathrm{Y}$ & 87 & 110.5 & 94.22 \\
\hline $\begin{array}{c}\text { Acoustic impedance Za } \\
\text { (MRayl) }\end{array}$ & 30 & 26.4 & 35.7 \\
\hline
\end{tabular}

Table 1. Piezoelectric, dielectric and mechanical properties of the KNLNTS, BNKLBT and PZT ceramics (Lee et al., 2009; Chan et al., 2008).

\begin{tabular}{|lcccccc|}
\hline & $\mathrm{c}_{11}^{\mathrm{E}}(\mathrm{GPa})$ & $\mathrm{c}_{12}^{\mathrm{E}}(\mathrm{GPa})$ & $\mathrm{c}_{13}^{\mathrm{E}}(\mathrm{GPa})$ & $\mathrm{c}_{33}^{\mathrm{E}}(\mathrm{GPa})$ & $\mathrm{c}_{44}^{\mathrm{E}}(\mathrm{GPa})$ & $\mathrm{c}_{66}^{\mathrm{E}}(\mathrm{GPa})$ \\
\hline KNLNTS & 195 & 124 & 64 & 173 & 32.7 & 35.3 \\
\hline BNKLBT & 146 & 53 & 41.8 & 147 & 47.4 & 46.7 \\
\hline & $\mathrm{e}_{15}\left(\mathrm{C} / \mathrm{m}^{2}\right)$ & $\mathrm{e}_{31}\left(\mathrm{C} / \mathrm{m}^{2}\right)$ & $\mathrm{e}_{33}\left(\mathrm{C} / \mathrm{m}^{2}\right)$ & $\varepsilon_{11}^{\mathrm{S}}$ & $\varepsilon_{33}^{\mathrm{S}}$ & $\rho$ \\
\hline KNLNTS & 8.4 & -16.3 & 11.4 & 614 & 746 & 4630 \\
\hline BNKLBT & 5.9 & -3.91 & 14.6 & 258 & 444 & 5780 \\
\hline
\end{tabular}

Table 2. Material parameters of the KNLNTS and BNKLBT ceramics (Lee et al., 2009; Chan et al., 2008). 


\section{Ultrasonic Wirebonding Transducers}

An ultrasonic wirebonding transducer is a device to provide ultrasonic energy to form intermetallic bond between a fine aluminium/gold wire and the bond pad of a chip in a wirebonding process. The schematic diagram of an Uthe 70PTL ultrasonic wirebonding transducer is shown in Figure 1. The transducer consists of three main parts: an ultrasonic driver, a horn and a wedge. The driver is a bolt-tightened Langevin transducer which is used to convert electrical energy into axial vibration along its length. It consists of four piezoelectric ceramic rings, which are connected electrically in parallel and mechanically in series and sandwiched between the front and back plates by a pre-stressed screw. The driver is operated at its fundamental axial mode (i.e. half-wave resonance) to provide maximum power efficiency. The horn has an exponential profile which couples and amplifies the axial vibration of the driver to provide a maximum vibration across the horn tip. The amplified vibration is then transmitted to the wedge tip, resulting in an oscillatory shear force parallel to the bonding wire and the bond pad surface. The wedge is fixed into a hole drilled at the horn tip by a small screw inserted axially so that it can be replaced for different IC packages and periodic quality assurance. The transducer is designed to operate at the 1.5-wavelength axial mode, i.e. the transducer (including the driver, the horn and the wedge) resonances at the second axial mode. For most of the commercial ultrasonic bonding systems, the operation frequency is around $65 \mathrm{kHz}$.

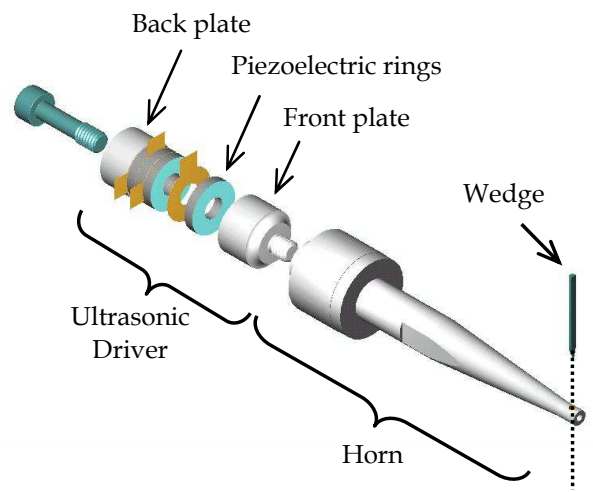

Fig. 1. Explosive diagram of the ultrasonic wirebonding transducer (Lee et al., 2009).

\section{Computational Analysis of Vibration Characteristics}

The overall performance of the transducer is affected not only by the dimensions of the components (which determine the resonance characteristics), but also by the material properties of the components, including the piezoelectric ceramic rings as the driving element and the front and back plates. Computer analysis of the vibration characteristics of the transducer hence becomes essential before the frication of a transducer with optimum performance. Finite element method (FEM) is a numerical simulation method commonly used for studying the performance of the transducer. In the following sections, FEM modeling, using a commercial code ANSYS 9.0, of the vibration characteristics of the KNLNTS ceramic rings and the corresponding KNLNTS transducers will be reported. 


\subsection{Ceramic Rings}

\subsubsection{Vibration Modes}

The finite element model of the ceramic ring is shown in Figure 2a. The outer diameter of the KNLNTS ceramic ring was fixed at $13.6 \mathrm{~mm}$ (for matching with the commercial transducers), while the inner diameter and thickness were varied in the ranges of 2 to $9 \mathrm{~mm}$ and 1.5 to $3.5 \mathrm{~mm}$, respectively. The ring was polarized along the thickness direction, and the electric field was applied on the top and bottom surfaces. The material parameters listed in Table 2 were used for the simulation. In general, five resonance modes are observed in the frequency range of $1 \mathrm{kHz}$ to $2 \mathrm{MHz}$. The simulated vibration mode shapes at each resonance mode and the (out-plane) surface displacement along the radial direction are shown in Figures $2 \mathrm{~b}-2 \mathrm{f}$. As the KNLNTS ceramic has been assumed to be lossless in the simulations, only the relative displacement is plotted. To confirm the simulation results, the surface displacement of a ceramic ring was also measured using a Polytec laser vibrometer, giving the results plotted in Figure 2 for comparison. It can be seen that mode 1, mode 2 and mode 4 are associated with the three fundamental resonance modes, namely the radial mode, wall thickness mode and thickness mode, respectively. Mode 3 and mode 5 are associated with the complex resonance modes, resulting from the coupling between vibrations along thickness and radial directions. The simulation results have shown that if the wall thickness (outer radius - inner radius) and thickness of the ring are closer, the resonance responses become more complicated.

\subsubsection{Dimension Optimization}

In practice, the operation of a bolt-tightened Langevin transducer is based on the thickness mode vibration of the driving element. Accordingly, the effective electromechanical coupling coefficient $\mathrm{k}_{\mathrm{eff}}$, for mode 4 is maximized. $\mathrm{k}_{\mathrm{eff}}$ is a measure of the conversion efficiency between electrical and mechanical energy at a particular resonance mode, and is defined as (Berlincourt et al., 1964):

$$
\mathrm{k}_{\text {eff }}=\sqrt{1-\left(\mathrm{f}_{\mathrm{r}} / \mathrm{f}_{\mathrm{a}}\right)^{2}}
$$

where $f_{r}$ and $f_{a}$ are the resonance and anti-resonance frequencies. Based on the simulated impedance spectra, $f_{r}, f_{a}$ and hence $k_{\text {eff }}$ were determined for ceramic rings with different inner diameters and thicknesses, giving the results shown in Figure 3. It can be seen that the calculated $k_{\text {eff }}$ depends on the dimensions of the ring, showing a maximum value at an inner diameter of $5.2 \mathrm{~mm}$ and a thickness of $2.3 \mathrm{~mm}$. 
(a)
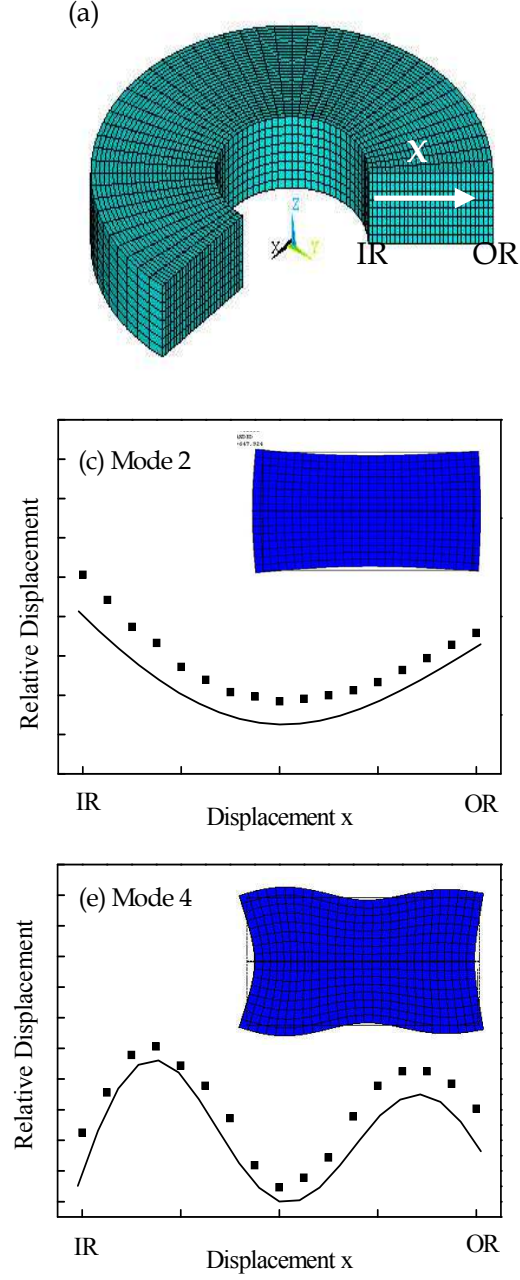
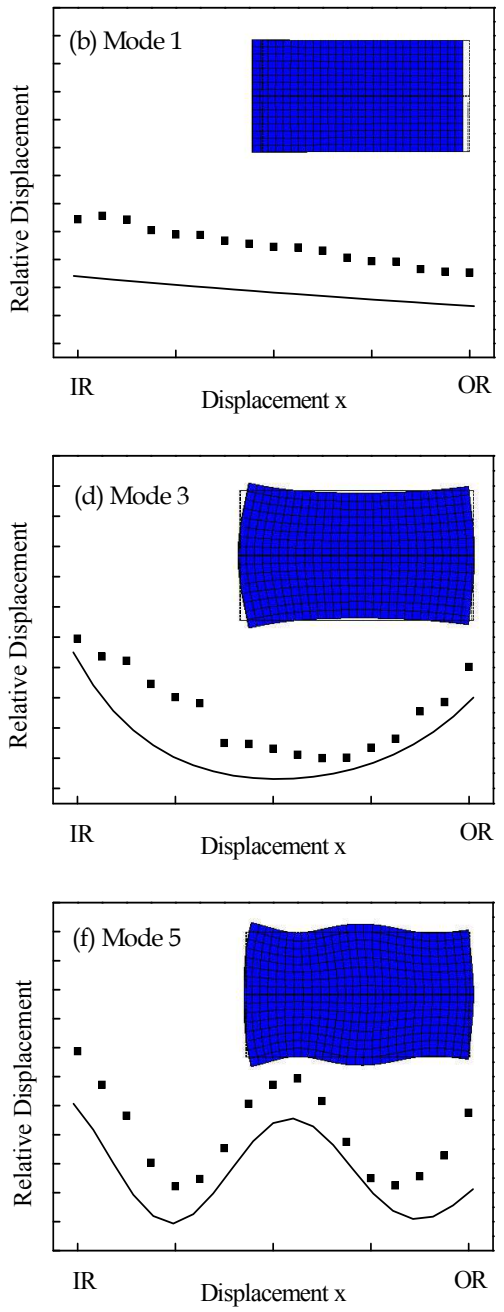

Fig. 2. Vibration mode shapes and the out-plane surface displacement profiles

(ם, experimental values; - , FEM values) for a ceramic ring at various resonance modes (Lee, 2008).

\subsection{Wirebonding Transducers}

As the transducer (except the wedge) had an axial-symmetry structure about its central (z) axis, they were modeled as a $360^{\circ}$ sector of elements with symmetry boundary conditions applied the $\mathrm{z}$ axis. Similar to the commercial transducers, the front and back plates were designed to have the same length. The shape and dimensions of the horn and wedge currently used in the commercial transducer were used. All the components, including the piezoelectric ceramic ring, were assumed to be lossless in the simulations, and the metal 

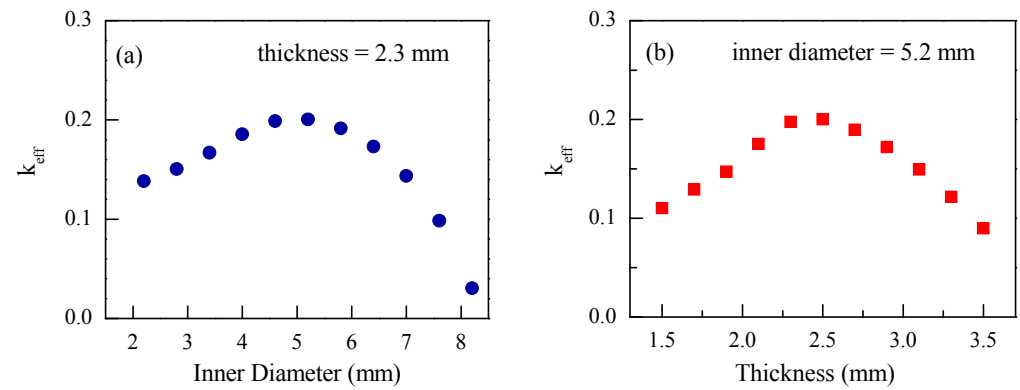

Fig. 3. Variations of $k_{\text {eff }}$ with (a) inner diameter and (b) thickness for the KNLNTS ceramic ring (Lee, 2008).

components were further assumed to be isotropic. For the ease of meshing, the thread of the pre-stressed screw was ignored, and the screw was simplified to be a cylindrical rod. Simplification was also made to the front plate where the thread and threaded bore were removed. The ring-shaped copper electrodes were assumed to be very thin, and thus were not included in the simulations. All the components in the assembly were assumed to have perfect mechanical coupling to each other. The h-type approach was applied to the simulations, and good convergence of the results was reached by successively increasing the number of solid elements and the number of nodes.

\subsubsection{Optimization of the Front and Back Plates}

Stainless steel is widely used for the front and back plates in the commercial PZT transducers. It is not expensive and has an acoustic impedance (46 MRayl) relatively close to that of PZT (Table 1). For transducer applications, a good match of the acoustic impedance between the ceramic driving elements and metal components is important, as it can promote the coupling of ultrasonic energy. As shown in Table 1, the KNLNTS ceramic has a lower acoustic impedance (30 MRayl) as compared to PZT. The coupling of ultrasonic energy may hence become inferior. Therefore, titanium alloy was used for the front and back plates in fabricating the KNLNTS transducer (abbreviated as KNLNTS-Ti transducer). The acoustic impedance of titanium alloy is about 27 MRayl, which is much closer to that of the KNLNTS ceramic. It is expected that the energy coupling and hence the performance of the KNLNTS transducer can be improved. For comparison purposes, KNLNTS transducers using stainless steel front and back plates (abbreviated as KNLNTS-SS transducer) were also fabricated.

Using the material properties listed in Table 2 and the optimum dimensions of the ceramic ring (outer diameter $=13.6 \mathrm{~mm}$, inner diameter $=5.2 \mathrm{~mm}$ and thickness $=2.3 \mathrm{~mm}$ ), the resonance frequencies of the KNLNTS-Ti transducer were simulated and the corresponding resonance modes were examined. The material parameters of the metal parts, including stainless steel and titanium alloy, used for the calculation can be found elsewhere (Lee, 2008). Based on the simulation results, the optimum dimensions of the front and back plates for fabricating a wirebonding transducer with an operation frequency near $65 \mathrm{kHz}$ were determined. The optimum length for the front and back plates for the KNLNTS-Ti 
transducer is $10.5 \mathrm{~m}$, while that for the KNLNTS-SS transducer is $8 \mathrm{~mm}$. It is noted that the length of the stainless steel plates currently used in the commercial wirebonding PZT transducers is also $8 \mathrm{~mm}$.

\subsubsection{Vibration modes}

The simulations have showed that there are a large number of resonance modes of the KNLNTS-Ti transducer. For example, 90 modes are found in the frequency range up to 150 $\mathrm{kHz}$. However, some of them, in particular those at high frequencies, are very weak, giving a very small effective electromechanical coupling coefficient $\left(k_{\text {eff }}<0.05\right)$. These modes cannot be excited effectively by the electrical driving signal in practice, so they are not considered. On the other hand, some of them are found to be excluded by the electrical boundary conditions and hence cannot be excited in practice.

Table 3 summarizes the effective modes for the KNLNTS-Ti transducer in the vicinity of the operation frequency $(65 \mathrm{kHz})$. The modes are named according to their sequence from the low frequency end. Based on the simulated mode shapes, the modes can be categorized into three main groups; namely the axial mode, the torsional mode, and the complex flexural mode. Mode 34 is the axial mode and has a resonance frequency of $65.798 \mathrm{kHz}$, suggesting that it is the operation mode. It is the 1.5 wavelength axial mode and has a maximum $k_{\text {eff }}$ of 0.317. The deformed shape and the axial profile of the transducer are plotted in Figure 4. The axial motion of the horn tip transmits to the wedge and causes the wedge to vibrate in a flexural manner. As shown in Figure $4 b$, the axial nodal point is located at the mounting barrel and the axial motion, after amplified by the horn profile, exhibits a maximum axial vibration at the horn tip. Physically, a pure axial excitation (of the ceramic ring) produces an axial front-to-back motion (along the length direction of the transducer) in the ultrasonic horn, which in turn, causes a large displacement at the tip of the wedge. As the motion is essentially in line with the wire to be bonded, the vibration mode is suitable for the operation.

The mode shapes for modes 31 to 38 are shown in Figure 5. Apart from the axial mode, the transducer can vibrate in other complex modes. For example, mode 33 is a flexural mode, making the wedge to vibrate in the left and right direction. At mode 37, the transducer vibrates in the up-and-down direction. As all the modes shown in Table 3 have a non-zero

\begin{tabular}{|c|c|c|c|c|}
\hline Mode number & $f_{\mathrm{r}}(\mathrm{Hz})$ & $f_{\mathrm{a}}(\mathrm{Hz})$ & $k_{\text {eff }}$ & Mode shape \\
\hline 31 & 53512 & 54889 & 0.220 & $1 \lambda$ Axial mode \\
\hline 32 & 57798 & 58327 & 0.130 & Complex mode \\
\hline 33 & 62502 & 62515 & 0.020 & Flexural mode \\
\hline 34 & 65798 & 69395 & 0.317 & $1.5 \lambda$ Axial mode \\
\hline 35 & 67146 & 67358 & 0.079 & Flexural mode \\
\hline 36 & 67407 & 67552 & 0.065 & Torsional mode \\
\hline 37 & 69739 & 70900 & 0.180 & Flexural mode \\
\hline 38 & 70019 & 70019 & 0.000 & Barrel mode \\
\hline
\end{tabular}

Table 3. Modal results of the KNLNTS-Ti transducer (Lee, 2008). 


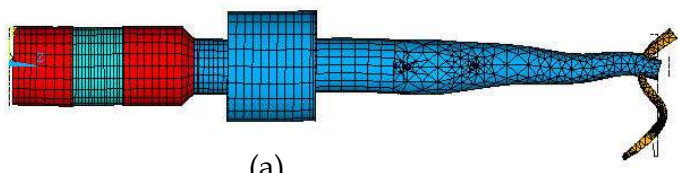

(a)

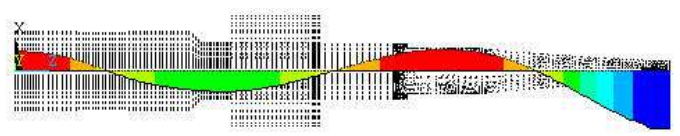

(b)

Fig. 4. (a) Deformed shape and (b) the axial vibration profile of the transducer at the 1.5- $\lambda$ axial mode (Lee, 2008; Lee et al., 2009).

$\mathrm{k}_{\text {eff, }}$ they can be excited in practice. However, the lateral flexural motions from side to side and the torsional motion are not desirable for the applications, as they would tend to deteriorate the bond quality as a result of diminishing the purity of the axial excitation through the loss of the input energy to other vibrations.

\section{Lead-Free Ultrasonic Wirebonding Transducers}

Similar to KNLNTS, BNKLBT ceramic rings were also used to fabricate the wirebonding transducers with either the titanium alloy front and back plates (abbreviated as BNKLBT-Ti transducer) or the stainless steel front and back plates (abbreviated as BNKLBT-SS transducer). BNKLBT also has a low acoustic impedance (26 MRayl), which is closer to that of titanium alloy (27 MRayl) than PZT (46 MRayl). The BNKLBT ceramic rings had an outer diameter of $12.7 \mathrm{~mm}$, an inner diameter of $5.1 \mathrm{~mm}$ and a thickness of $2.3 \mathrm{~mm}$. Following similar procedures, the optimum length for the front and back plates for the BNKLBT-Ti transducer was determined as $10 \mathrm{~m}$, while that for the BNKLBT-SS transducer was $8 \mathrm{~mm}$. For comparison purposes, PZT transducer, with stainless steel front and back plates, (abbreviated as PZT-SS) was fabricated. The PZT ceramic rings (APC 840), supplied by American Piezo Ceramics Inc., are the same as those currently used in the commercial wirebonding transducers. A photograph of the ultrasonic drivers for the KNLNTS-Ti and KNLNTS-SS transducers is shown in Figure 6a, while a photograph of the KNLNTS-Ti transducer is shown in Figure 6b.

\subsection{Electrical Characteristics}

The electrical impedance and phase spectra (measured using an HP 4294A impedance analyzer) of the KNLNTS-Ti, KNLNTS-SS, BNKLBT-Ti, BNKLBT-SS and PZT-SS transducers are shown in Figure 7. It can be seen that the strongest resonance mode for all the transducers occurs in the frequency range of $62-68 \mathrm{kHz}$, i.e. in vicinity of the designed operating frequency $65 \mathrm{kHz}$. At this resonance frequency, the transducer vibrates in the 1.5$\lambda$ axial mode, providing a large front-to-back vibration at the tip of the wedge. As compared to the PZT-SS transducer, the lead-free transducers exhibit less spurious vibrations; but the 
operating mode is weaker and the impedance at resonance frequency $\left(Z_{\mathrm{f}}\right)$ is higher. The observed $Z_{\mathrm{f}}$ for the KNLNTS-Ti, KNLNTS-SS, BNKLBT-Ti and BNKLBT-SS transducers are $120 \Omega, 200 \Omega$ and $130 \Omega$ and $130 \Omega$, respectively, while that for the PZT-SS transducer is $20 \Omega$.
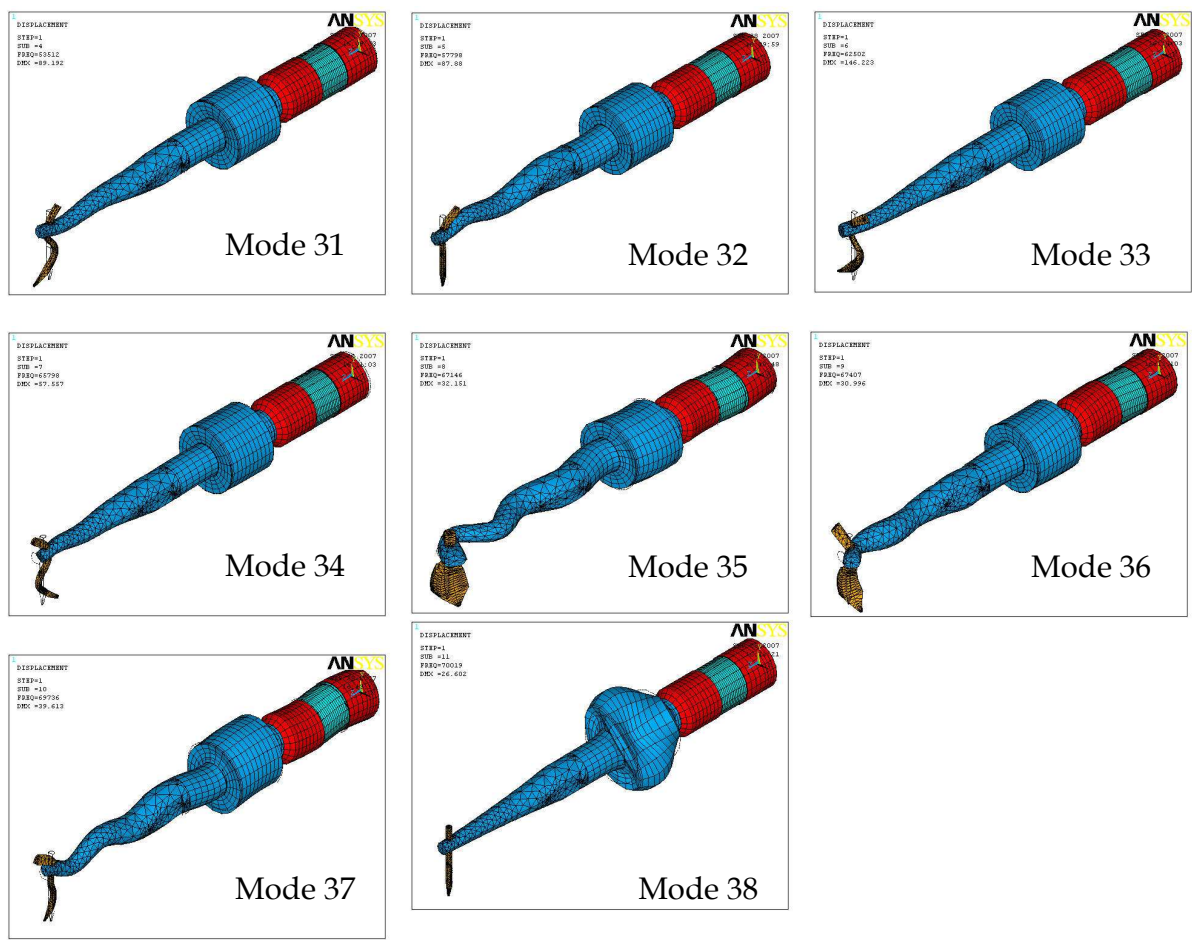

Fig. 5. Mode shapes for the resonance modes around $65 \mathrm{kHz}$ (Lee, 2008).

(a)

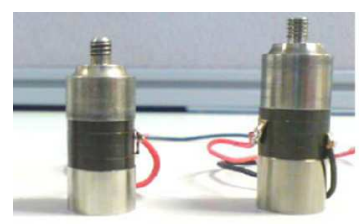

KNLNTS-SS KNLNTS-Ti (b)

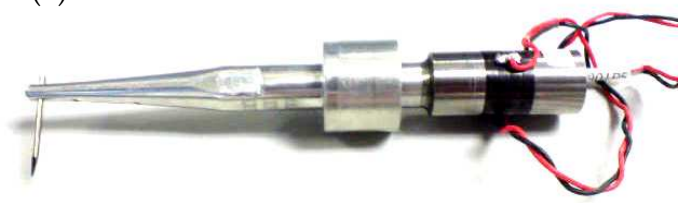

Fig. 6. Photographs of (a) the drivers for the KNLNTS transducers, and (b) the KNLNTS-Ti wirebonding transducer prototype (Lee et al., 2009). 

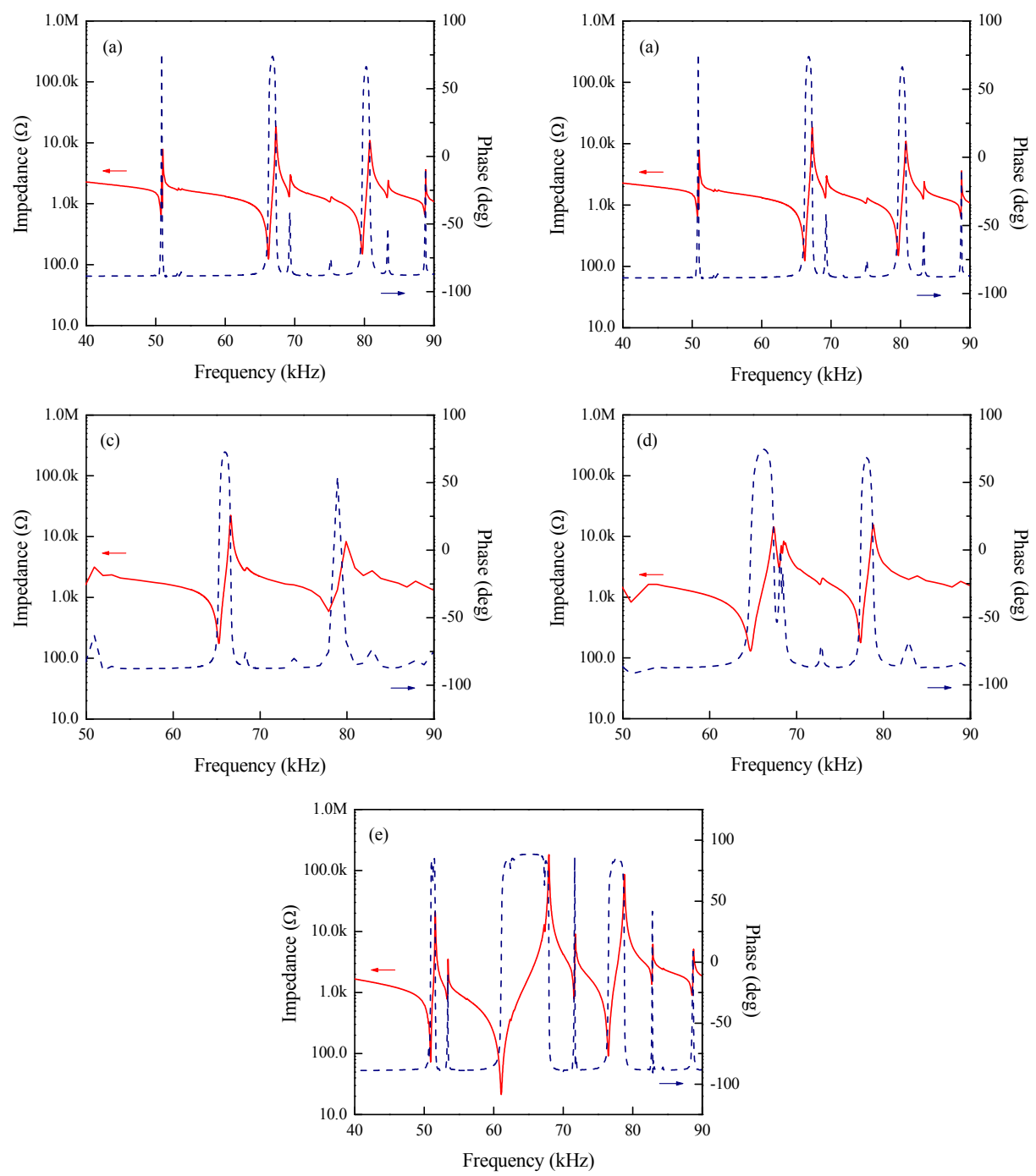

Fig. 7. Frequency plot of the electrical impedance and phase angle for the transducer prototypes: (a) KNLNTS-Ti, (b) KNLNTS-SS, (c) BNKLBT-Ti, (d) BNKLBT-SS; and (e) PZTSS (Lee et al., 2009; Chan et al., 2008).

\subsection{Vibrational Characteristics}

As the vibration of the wedge tip is directly related to the wirebonding operation, the vibration characteristic of the wedge was important and hence was investigated. The transducer was affixed to a sample holder with similar clamping conditions to a wirebonding machine. An ultrasonic generator operating in a digital phase-locked-loop 


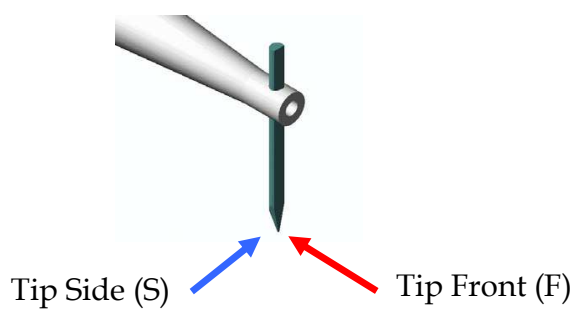

Fig. 8. Schematic diagram showing the positions of the vibration measurement. The arrows indicate the incidence of the laser beam and hence the vibration direction (Lee et al., 2009).

mode was used to drive the transducers at the corresponding resonance frequency and a constant power of $0.1 \mathrm{~W}$. The vibrations at the front of the wedge tip (or tip front) and the side of the wedge tip (or tip side), were measured, using a Polytec laser Doppler vibrometer (OFV-303 and OFV-3001 controller processor). Figure 8 shows schematically the positions of the measurements.

Figure 9 shows, as an example, the temporal profile of the axial displacement at the tip front of the KNLNTS-Ti transducer. During the bonding process, envelop of sine waves at the transducer resonance frequency is sent to the transducer. As it takes time for the transducer

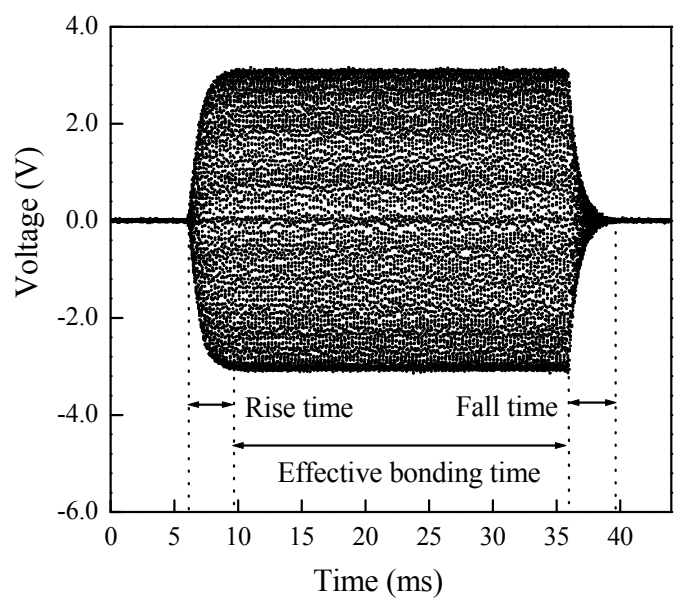

Fig. 9. Axial vibration response at the tip front of the KNLNTS-Ti transducer (Lee, 2008).

to response to the excitation for increasing or decreasing the vibration amplitude to the desired level, there exists response times called the rise time or fall time as shown in the temporal profile (Fig. 9). It has been found that both the rise and fall times for the lead-free transducers are about a few milliseconds, which are comparable to those of the PZT-SS transducer.

The observed vibration amplitudes at different positions of the transducers are compared in 
Table 4. It can be seen that the vibration amplitudes at the tip front of the KNLNTS-Ti and BNKLBT-Ti transducers are larger ( $65 \%)$ than those of the KNLNTS-SS and BNKLBT-SS transducers. This should be attributed to the better match of the acoustic impedances between the lead-free ceramics and the titanium alloy plates. By the converse piezoelectric effect, the piezoelectric ceramic ring converts electrical energy to mechanical energy. The mechanical energy is the source of the vibration, firstly transferred to the metal plates in the driver and then transferred to the horn. The acoustic impedance between the piezoelectric ceramics and the metal plates (front and back plates) is a critical factor that determined the efficiency of energy transfer in the ultrasonic wirebonding transducer. A better match of the acoustics impedances results in an increase in efficiency and hence an improvement in axial vibration performance.

\begin{tabular}{|l|c|c|c|}
\hline & Tip Front $(\mu \mathrm{m})$ & Tip Side $(\mu \mathrm{m})$ & F/S ratio \\
\hline KNLNTS-Ti & 1.728 & 0.046 & 37.6 \\
\hline KNLNTS-SS & 1.093 & 0.035 & 31.2 \\
\hline BNKLBT-Ti & 1.669 & 0.082 & 20.2 \\
\hline BNKLBT-SS & 0.956 & 0.085 & 11.3 \\
\hline PZT-SS & 1.693 & 0.191 & 8.9 \\
\hline
\end{tabular}

Table 4. Vibration amplitudes of the transducers driven at the corresponding resonance frequency and a constant power of 0.1W (Lee et al., 2009; Chan et al., 2008).

With the use of the titanium alloy front and back plates, both the lead-free transducers exhibit a large vibration at the tip front, $\sim 1.7 \mu \mathrm{m}$, which is very close to that of the PZT-SS transducer (Table 4). However, the PZT-SS transducer produces a larger lateral vibration, giving a larger vibration amplitude at the tip side $(0.191 \mu \mathrm{m})$ and thus a smaller ratio of the axial displacement to the lateral displacement, especially the F/S ratio. It should be noted that the actual vibrations of the wedge tip during wire-bonding may be different from the measurements on an un-loaded wedge tip (as shown in Table 4). Nevertheless, it is apparent that a large lateral vibration will produce a large bond width which is not desirable for real applications, in particular for miniaturization. As shown in Table 4, both the KNLNTS-Ti and BNKLBT-Ti transducers give a smaller lateral vibration $(0.046$ and $0.082 \mu \mathrm{m}$, respectively). This should be attributed to the low electromechanical coupling coefficient in the lateral direction $\left(\mathrm{k}_{31}\right)$ of the ceramics (Table 1). The transfer of energy to the lateral vibration at the driving element is small, so the lateral vibration of the tip is effectively reduced. Similar results have been reported for the transducers using 1-3 ceramic/polymer composites as the driving element (Chong et al., 2004). $\mathrm{k}_{31}$ of a 1-3 composite is generally reduced, so the performance of the composite transducer is enhanced.

The output power of the ultrasonic wirebonding transducer can be varied in different bonding conditions and the output power is determined by the electrical input power. It is important to have a transducer with high stability for industrial applications. The vibrations at the tip front and tip side for the transducers at different powers are shown in Figures 10. In general, all the vibration displacements increase with increasing power. However, it is seen that the $\mathrm{F} / \mathrm{S}$ ratio remains almost unchanged at different powers. 

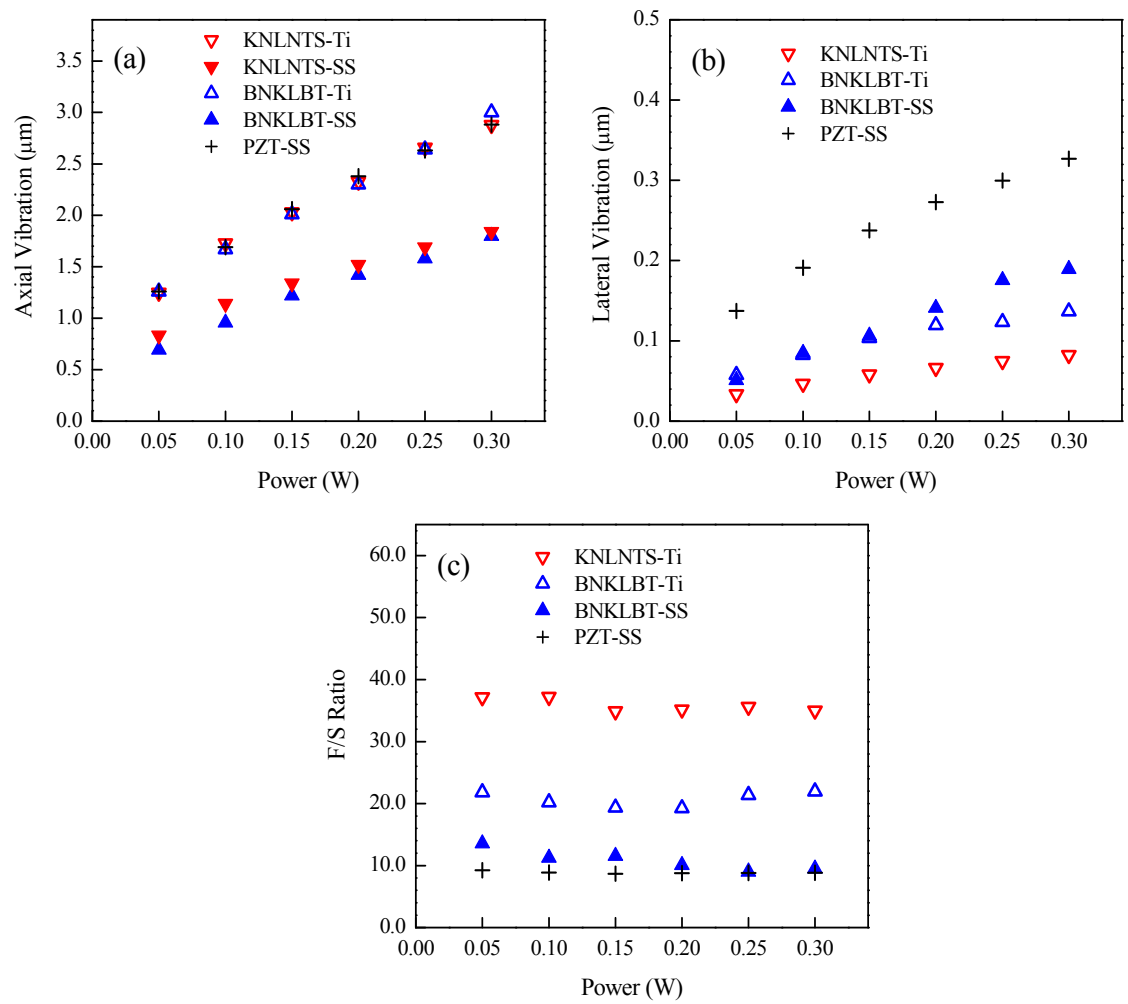

Fig. 10. Variations of (a) the vibration at the tip front, (b) the vibration at the tip side and (c) the F/S ration with input power. (Lee, 2008; Chan et al., 2008).

\subsection{Wire-bonding Performance}

The KNLNTS-Ti transducer was mounted on an automatic wire bonder (ASM AB530) for evaluating the wire-bonding performance (Fig. 11). A print circuit board (PCB) consisting of a standard die (ASM 96AAA) and a number of gold-plated bond pads was used for the evaluation. In each test, an aluminum wire with a diameter of $25 \mu \mathrm{m}$ was first bonded on the die ( $1^{\text {st }}$ bond) and then on the bond pad of the PCB ( $2^{\text {nd }}$ bond) under a bond force of 0.30 $\mathrm{N}$. The transducer was driven at $320 \mathrm{~mW}$ for the $1^{\text {st }}$ bond and $390 \mathrm{~mW}$ for the $2^{\text {nd }}$ bond, both for a duration of $20 \mathrm{~ms}$. The quality of the bonded wire was examined by an microscope with a 200-times magnification for a visual inspection and then by a pull tester for a standard pull test. The visual inspection involves visual checking of the appearance and deformation ratio of each bond point, while the pull test is a destructive test aiming to measure the pull force of each bonded wire by pulling it at its loop top vertically until rupture occurs. The term good bond is defined as a wire bond possessing both higher pull force and smaller deformation ratio with smaller standard deviations. The most desirable case is breaking at the wire span followed by breaking at the bond neck. For a poor bond, it may be completely peeled off from the bonding surface in the pull test because of the weak 


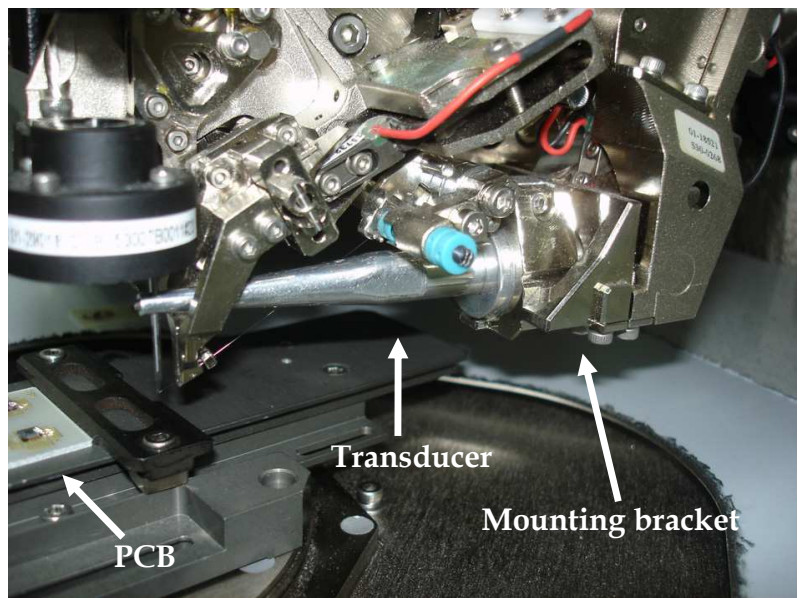

Fig. 11. Photograph showing a KNLNTS-Ti transducer mounted in the bracket of the bondhead assembly of an ASM model AB530 automatic wire bonder for bonding gold-plated printed circuit boards (Lee, 2008).

intermetallic adhesion between the wire and the bonding surface. For the nonstick bond, the wire cannot stick on the bonding surface on the completion of the whole bonding period.

The SEM micrographs of the bonds are shown in Figures 12a-c. The wire deformation is usually characterized by a ratio of the bond width to the diameter of the wire $\mathrm{D}(25 \mu \mathrm{m})$. The deformation ratio produced by the KNLNTS-Ti transducer is about 1.60D, which is relatively small as compared to that produced by the (commercial) PZT-SS transducers (1.94D). This is in good agreement with the vibration amplitude measurements (Table 4) and should be attributed to the small lateral vibration of the KNLNTS-Ti transducer. There was no bond failure during bonding, and most of the failures for the pull test were neck break (Fig. 12d) with a few exception of weld off. This indicates that the adhesion in the interfaces of the bond wire and the bonding surface is good. The averaged pull strength (the maximum force applied to the wire in the pull test) is about $0.5 \mathrm{~N}$, which clearly exceeds the industrial requirement $(0.4 \mathrm{~N})$. All these results clearly show that the KNLNTS-Ti transducer is ready for use in the wirebonding applications.

\section{Conclusion}

Lead-free KNLNTS and BNKLBT piezoelectric ceramic rings have been successfully prepared and used as the driving elements for fabricating ultrasonic wirebonding transducers. In order to improve the energy transfer between different parts of the transducer, titanium alloy has been used to fabricate the front and back plates. The dimensions of the ceramic rings and the titanium alloy plates have been optimized to give an operation frequency of $\sim 65 \mathrm{kHz}$. Because of the better matching of the acoustic impedances, an effective transfer of vibration energy is achieved in the KNLNTS-Ti and BNKLBT-Ti transducers, leading to a large axial vibration $(\sim 1.7 \mu \mathrm{m}$ at $0.1 \mathrm{~W})$. Probably attributed to the low planar electromechanical coupling coefficient $k_{31}(0.26$ and 0.188 , 


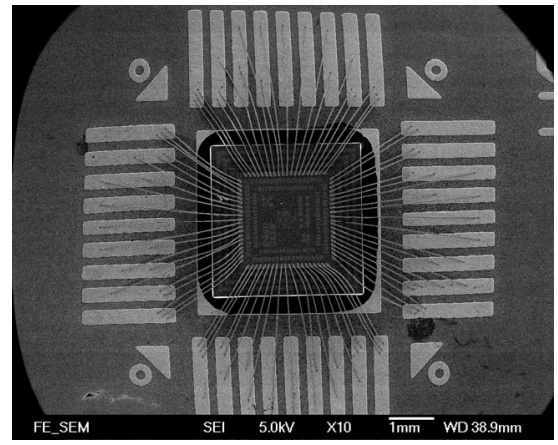

(a)

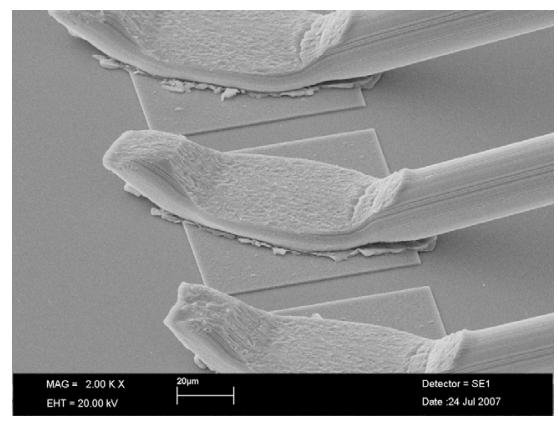

(c)

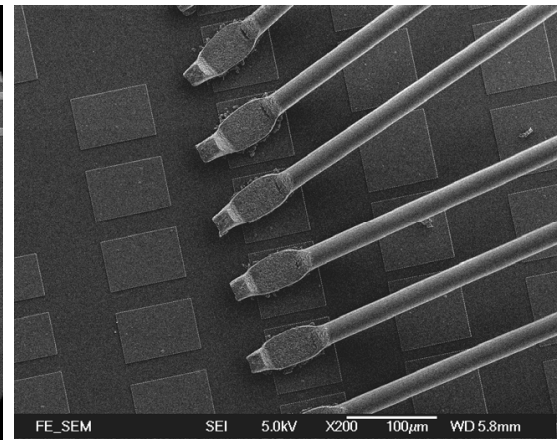

(b)

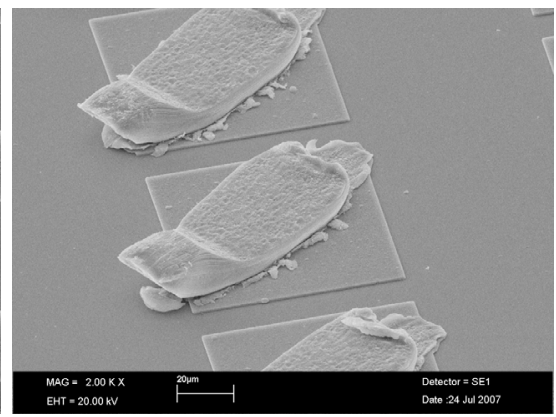

(d)

Fig. 12. SEM micrographs of (a) a chip bonded with wires, (b) the top view of the $1^{\text {st }}$ bonc (c) the side view of the $1^{\text {st }}$ bond, and (d) the neck break of $1^{\text {st }}$ bond after the pull test (Lee al., 2009).

respectively), the lead-free transducers exhibits a small lateral vibration $(0.046$ and $0.082 \mu \mathrm{m}$, respectively, at $0.1 \mathrm{~W})$, which is smaller than that of the PZT transducer $(0.191 \mu \mathrm{m})$ and is essential for producing a small or narrow bond. Moreover, the KNLNTS-Ti transducer has successfully bonded the aluminum wire on the standard die and gold-plated PCB. The bonds are of good quality, having a small deformation ratio $(1.60 \mathrm{D}$ vs. $1.94 \mathrm{D}$ for the PZT transducer) and high bond strength $(>0.4 \mathrm{~N})$. These clearly show that the KNLNTS and BNKLBT lead-free piezoelectric ceramics are promising candidates for replacing the leadbased ceramics as a driving element in the future generation of wire bonders.

\section{Acknowledgments}

The authors would like to acknowledge supports from the Research Committee (A/C code 1-ZV6Y) and the Centre for Smart Materials of The Hong Kong Polytechnic University. 


\section{References}

Ahn, C.W.; Song, H.C.; Nahm, S.; Park, S.H.; Uchino, K.; Priya, S.; Lee, H.G.; Kang, N.K.(2005). Effect of $\mathrm{MnO}_{2}$ on the piezoelectric properties of (1-x) $\left(\mathrm{Na}_{0.5} \mathrm{~K}_{0.5}\right) \mathrm{NbO}_{3}$ xBaTiO ${ }_{3}$ ceramics. Japanese Journal of Applied Physics Part 2 44: L1361-L1364.

Berlincourt, D.A.; Curran, D.R.; Jaffe, H. (1964). Piezoelectric and piezomagnetic materials and their function in transducer. Physical Acoustics. W. P. Mason. New York, Academic Press. 1, 169.

Chan, H.L.W.; Choy, S.H.; Chong, C.P.; Li, H.L.; Liu, P.C.K. (2008). Bismuth sodium titanate based lead-free ultrasonic transducer for microelectronics wirebonding applications. Ceramics International 34: 773-777.

Chong, C.P.; Li, H.L.; Chan, H.L.W.; Liu, P.C.K. (2004). Study of 1-3 composite transducer for ultrasonic wirebonding application. Ceramics International 30: 1141-1146.

Choy, S.H.; Wang, X.X.; Chan, H.L.W.; Choy, C.L. (2007). Electromechanical and ferroelectric properties of $\left(\mathrm{Bi}_{1 / 2} \mathrm{Na}_{1 / 2}\right) \mathrm{TiO}_{3}-\left(\mathrm{Bi}_{1 / 2} \mathrm{~K}_{1 / 2}\right) \mathrm{TiO}_{3}-\left(\mathrm{Bi}_{1 / 2} \mathrm{Li}_{1 / 2}\right) \mathrm{TiO}_{3}-\mathrm{BaTiO}_{3}$ lead-free piezoelectric ceramics for accelerometer. Applied Physics A 89: 775-781.

Fan, G.; Lu, W.; Wang, X.; Liang, F. (2007). Morphotropic phase boundary and piezoelectric properties of $\mathrm{Bi}_{0.5} \mathrm{Na}_{0.5} \mathrm{TiO}_{3}-\mathrm{Bi}_{0.5} \mathrm{~K}_{0.5} \mathrm{TiO}_{3}-\mathrm{KNbO}_{3}$ lead-free piezoelectric ceramics. Applied Physics Letters 91: 202908.

Fan, G.; Lu, W.; Wang, X.; Liang, F.; Xiao, J. (2008). Phase transition behaviour and electromechanical properties of $\left(\mathrm{Na}_{1 / 2} \mathrm{Bi}_{1 / 2}\right) \mathrm{TiO}_{3}-\mathrm{KNbO}_{3}$ lead-free piezoelectric ceramics. Journal of Physics D 41: 035403.

Guo, Y.P.; Kakimoto, K.; Ohsato, H. (2004). Phase transitional behavior and piezoelectric properties of $\left(\mathrm{Na}_{0.5} \mathrm{~K}_{0.5}\right) \mathrm{NbO}_{3}-\mathrm{LiNbO}_{3}$ ceramics. Applied Physics Letters 85: 41214123.

Guo, Y.P.; Kakimoto, K; Ohsato, H. (2005). ( $\left.\mathrm{Na}_{0.5} \mathrm{~K}_{0.5}\right) \mathrm{NbO}_{3}-\mathrm{LiTaO}_{3}$ lead-free piezoelectric ceramics. Materials Letters 59: 241-244.

Hiruma, Y.; Imai, Y.; Watanabe, Y.; Nagata, H.; Takenaka, T. (2008). Large electrostrain near the phase transition temperature of $\left(\mathrm{Bi}_{0.5} \mathrm{Na}_{0.5}\right) \mathrm{TiO}_{3}-\mathrm{SrTiO}_{3}$ ferroelectric ceramics. Applied Physics Letters 92: 262904.

Jaeger, R.E. and Egerton, L. (1962). Hot pressing of potassium-sodium niobates. Journal of the American Ceramic Society 45: 209-213.

Kounga, A.B.; Zhang, S.T.; Jo, W.; Granzow, T.; Rodel, J. (2008). Morphotropic phase boundary in (1-x) $\mathrm{Bi}_{0.5} \mathrm{Na}_{0.5} \mathrm{TiO}_{3}-\mathrm{xK}_{0.5} \mathrm{Na}_{0.5} \mathrm{NbO}_{3}$ lead-free piezoceramics. Applied Physics Letters 92: 222902.

Lee, T. (2008). Development of lead-free ultrasonic wirebonding transducers for microelectronic packaging applications. MPhil Thesis: The Hong Kong Polytechnic University.

Lee, T.; Kwok, K.W.; Chan, H.L.W. (2008). Preparation and piezoelectric properties of $\mathrm{CeO}_{2-}$ added $\left(\mathrm{Na}_{0.455} \mathrm{~K}_{0.475} \mathrm{Li}_{0.05}\right)\left(\mathrm{Nb}_{0.92} \mathrm{Ta}_{0.05} \mathrm{Sb}_{0.03}\right) \mathrm{O}_{3}$ lead-free ceramics. Journal of Physics D 41: 155402.

Lee, T.; Kwok, K.W.; Li, H.L.; Chan, H.L.W. (2009). Lead-free alkaline niobate-based transducer for ultrasonic wirebonding applications. Sensors Actuator A 150: 267271.

Li, Y.; Chen, W.; Xu, Q.; Zhou, J.; Wang, Y.; Sun, H. (2007). Piezoelectric and dielectric properties of $\mathrm{CeO}_{2}$-doped $\mathrm{Bi}_{0.5} \mathrm{Na}_{0.44} \mathrm{~K}_{0.06} \mathrm{TiO}_{3}$ lead-free ceramics. Ceramics International 33: 95-99. 
Li, Y.M.; Chen, W.; Xu, Q.; Zhou, J.; Gu, X.; Fang, S. (2005). Electromechanical and dielectric properties of $\mathrm{Na}_{0.5} \mathrm{Bi}_{0.5} \mathrm{TiO}_{3}-\mathrm{K}_{0.5} \mathrm{Bi}_{0.5} \mathrm{TiO}_{3}-\mathrm{BaTiO}_{3}$ lead-free ceramics. Materials Chemistry and Physics 94: 328-332.

Lin, D.M.; Kwok, K.W.; Lam, K.H.; Chan, H.L.W. (2007a). Dielectric and piezoelectric properties of $\left(\mathrm{K}_{0.5} \mathrm{Na}_{0.5}\right) \mathrm{NbO}_{3}-\mathrm{Ba}\left(\mathrm{Ti}_{0.95} \mathrm{Zr}_{0.05}\right) \mathrm{O}_{3}$ lead-free ceramics. Applied Physics Letters 91: 143513.

Lin, D.M.; Kwok, K.W.; Chan, H.L.W. (2007b). Structure and electrical properties of $\mathrm{K}_{0.5} \mathrm{Na}_{0.5} \mathrm{NbO}_{3}-\mathrm{LiSbO}_{3}$ lead-free piezoelectric ceramics. Journal of Applied Physics 101: 074111.

Lin, D.M.; Kwok, K.W.; Chan, H.L.W. (2008a). Phase transition and electrical properties of $\left(\mathrm{K}_{0.5} \mathrm{Na}_{0.5}\right)\left(\mathrm{Nb}_{1-\mathrm{x}} \mathrm{Ta}_{\mathrm{x}}\right) \mathrm{O}_{3}$ lead-free piezoelectric ceramics. Applied Physics A 91: 167171.

Lin, D.M.; Kwok, K.W.; Chan, H.L.W. (2008b). Piezoelectric and ferroelectric properties of $\mathrm{Cu}$-doped $\mathrm{K}_{0.5} \mathrm{Na}_{0.5} \mathrm{NbO}_{3}$ lead-free ceramics. Journal of Physics D 41: 045401.

Makiuchi, Y.; Aoyagi, R.; Hiruma, Y.; Nagata, H.; Takenaka, T. (2005). ( $\left(\mathrm{Bi}_{1 / 2} \mathrm{Na}_{1 / 2}\right) \mathrm{TiO}_{3}-$ $\left(\mathrm{Bi}_{1 / 2} \mathrm{~K}_{1 / 2}\right) \mathrm{TiO}_{3}-\mathrm{BaTiO}_{3}$-based lead-free piezoelectric ceramics. Japanese Journal of Applied Physics Part 144 (6B): 4350-4353.

Matsubara, M.; Kikuta, K.; Hirano, S. (2005). Piezoelectric properties of $\left(\mathrm{K}_{0.5} \mathrm{Na}_{0.5}\right)\left(\mathrm{Nb}_{1-}\right.$ $\left.{ }_{x} \mathrm{Ta}_{\mathrm{x}}\right) \mathrm{O}_{3}-\mathrm{K}_{5.4} \mathrm{Cu}_{1.3} \mathrm{Ta}_{10} \mathrm{O}_{29}$. Journal of Applied Physics 97: 114105.

Nagata, H.; Yoshida, M.; Makiuchi, Y.; Takenaka, T. (2003). Large piezoelectric constant and high Curie temperature of lead-free piezoelectric ceramic ternary system based on bismuth sodium titanate-bismuth potassium titanate-barium titanate near the morphotropic phase boundary. Japanese Journal of Applied Physics Part 142 (12): 7401-7403.

Saito, Y.; Takao, H.; Tani, T.; Nonoyama, T.; Takatori, K.; Homma, T.; Nagaya, T.; Nakamura, M. (2004). Lead-free piezoceramics. Nature 432: 84-87.

Smolenskii, G.A.; Isupov, V.A.; Agranovskaya, A.I.; Krainik, N.N. (1961). New ferroelectrics of complex composition. Soviet Physics-Solid State (English Translation) 2 (11): 2651-2654.

Takennaka, T.; Maruyama, K.; Sakata, K. (1991). $\left(\mathrm{Ba}_{1 / 2} \mathrm{Na}_{1 / 2}\right) \mathrm{TiO}_{3}-\mathrm{BaTiO}_{3}$ system for leadfree piezoelectric ceramics. Japanese Journal of Applied Physics Part 230 (9B): 2236-2239.

Wang, X.X.; Choy, S.H.; Tang, X.G.; Chan, H.L.W. (2005). Dielectric behavior and microstructure of $\left(\mathrm{Bi}_{1 / 2} \mathrm{Na}_{1 / 2}\right) \mathrm{TiO}_{3}-\left(\mathrm{Bi}_{1 / 2} \mathrm{~K}_{1 / 2}\right) \mathrm{TiO}_{3}-\mathrm{BaTiO}_{3}$ lead-free piezoelectric ceramics. Journal of Applied Physics 97: 104101.

Wang, X.X.; Tang, X.G.; Chan, H.L.W. (2004a). Electromechanical and ferroelectric properties of $\mathrm{Bi}_{0.5} \mathrm{Na}_{0.5} \mathrm{TiO}_{3}-\mathrm{Bi}_{0.5} \mathrm{~K}_{0.5} \mathrm{TiO}_{3}-\mathrm{BaTiO}_{3}$ lead-free piezoelectric ceramics. Applied Physics Letters 85: 91-93.

Wang, X.X.; Kwok, K.W.; Tang, X.G.; Chan H.L.W.; Choy, C.L. (2004b). Electromechanical properties and dielectric behavior of $\left(\mathrm{Bi}_{1 / 2} \mathrm{Na}_{1 / 2}\right)_{1-1.5 \times} \mathrm{Bi}_{x} \mathrm{TiO}_{3}$ lead-free piezoelectric ceramics. Solid State Communications 129: 319-323.

Xu, C.G.; Lin, D.M.; Kwok, K.W. (2008). Structure, electrical properties and depolarization temperature of $\left(\mathrm{Bi}_{0.5} \mathrm{Na}_{0.5}\right) \mathrm{TiO}_{3}-\mathrm{BaTiO}_{3}$ lead-free piezoelectric ceramics. Solid State Sciences 10: 934-940. 
Yao, Y.Q.; Tseng, T.Y.; Chou, C.C.; Chen, H.H.D. (2007). Phase transition and piezoelectric property of $\left(\mathrm{Bi}_{0.5} \mathrm{Na}_{0.5}\right)_{0.94} \mathrm{Ba}_{0.06} \mathrm{Zr}_{\mathrm{y}} \mathrm{Ti}_{1-\mathrm{y}} \mathrm{O}_{3}(\mathrm{y}=0-0.04)$ ceramics. Journal of Applied Physics 102: 094102.

Yoshii, K.; Hiruma, Y.; Nagata, H.; Takenaka, T. (2006). Electrical properties and depolarization temperature of $\mathrm{Bi}_{1 / 2} \mathrm{Na}_{1 / 2} \mathrm{TiO}_{3}-\mathrm{B}_{1 / 2} \mathrm{~K}_{1 / 2} \mathrm{TiO}_{3}$ lead-free piezoelectric ceramics. Japanese Journal of Applied Physics Part 2 45: 4493-4496.

Yu H.; Ye, Z.G. (2008). Dielectric, Ferroelectric and piezoelectric properties of the lead-free (1-x) $\left(\mathrm{Na}_{0.5} \mathrm{Bi}_{0.5}\right) \mathrm{TiO}_{3}-\mathrm{xBiAlO}{ }_{3}$ solid solution. Applied Physics Letters 93: 112902.

Zhou C.; Liu, X. (2008). Effect of B-Site substitution of complex ions on dielectric and piezoelectric properties in $\left(\mathrm{Bi}_{1 / 2} \mathrm{Na}_{1 / 2}\right) \mathrm{TiO}_{3}$ piezoelectric ceramics. Materials Chemistry and Physics 108: 413-416.

Zhou, C.; Liu, X.; Li, W.; Yuan, C. (2009). Structure and piezoelectric properties of $\mathrm{Bi}_{0.5} \mathrm{Na}_{0.5} \mathrm{TiO}_{3}-\mathrm{Bi}_{0.5} \mathrm{~K}_{0.5} \mathrm{TiO}_{3}-\mathrm{BiFeO}_{3}$ lead-free piezoelectric ceramics. Materials Chemistry and Physics 114: 832-836.

Zuo, R.; Fang, X.; Ye, C. (2007). Phase structures and electrical properties of new lead-free $\left(\mathrm{Na}_{0.5} \mathrm{~K}_{0.5}\right) \mathrm{NbO}_{3}-\left(\mathrm{Bi}_{0.5} \mathrm{Na}_{0.5}\right) \mathrm{TiO}_{3}$ ceramics. Applied Physics Letters 90: 092904.

Zuo, R.; Ye, C.; Fang, X.; Li, J. (2008). Tantalum doped 0.94 $\mathrm{Bi}_{0.5} \mathrm{Na}_{0.5} \mathrm{TiO}_{3}-0.06 \mathrm{BaTiO}_{3}$ piezoelectric ceramics. Journal of the European Ceramic Society 28: 871-877. 


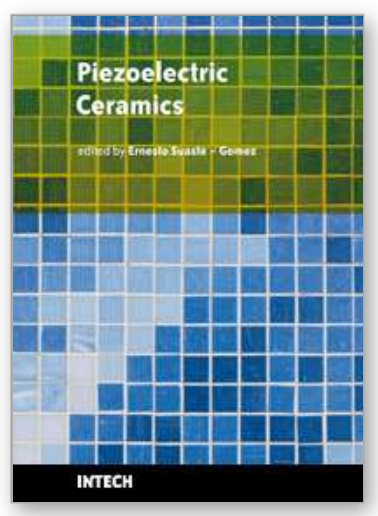

\author{
Piezoelectric Ceramics \\ Edited by Ernesto Suaste-Gomez
}

ISBN 978-953-307-122-0

Hard cover, 294 pages

Publisher Sciyo

Published online 05, October, 2010

Published in print edition October, 2010

This book reviews a big window of opportunity for piezoelectric ceramics, such as new materials, material combinations, structures, damages and porosity effects. In addition, applications of sensors, actuators, transducers for ultrasonic imaging, positioning systems, energy harvesting, biomedical and microelectronic devices are described. The book consists of fourteen chapters. The genetic algorithm is used for identification of RLC parameters in the equivalent electrical circuit of piezoelectric transducers. Concept and development perspectives for piezoelectric energy harvesting are described. The characterization of principal properties and advantages of a novel device called ceramic-controlled piezoelectric with a Pt wire implant is included. Biocompatibility studies between piezoelectric ceramic material and biological cell suspension are exposed. Thus, piezoelectric ceramics have been a very favorable solution as a consequence of its high energy density and the variety of fabrication techniques to obtain bulk or thin films devices. Finally, the readers will perceive a trend analysis and examine recent developments in different fields of applications of piezoelectric ceramics.

\title{
How to reference
}

In order to correctly reference this scholarly work, feel free to copy and paste the following:

K.W. Kwok, T. Lee, S.H. Choy and H.L.W. Chan (2010). Lead-Free Piezoelectric Transducers for Microelectronic Wirebonding Applications, Piezoelectric Ceramics, Ernesto Suaste-Gomez (Ed.), ISBN: 978953-307-122-0, InTech, Available from: http://www.intechopen.com/books/piezoelectric-ceramics/lead-freepiezoelectric-transducers-for-microelectronic-wirebonding-applications-

\section{INTECH}

open science | open minds

\section{InTech Europe}

University Campus STeP Ri

Slavka Krautzeka 83/A

51000 Rijeka, Croatia

Phone: +385 (51) 770447

Fax: +385 (51) 686166

www.intechopen.com

\section{InTech China}

Unit 405, Office Block, Hotel Equatorial Shanghai

No.65, Yan An Road (West), Shanghai, 200040, China

中国上海市延安西路65号上海国际贵都大饭店办公楼 405 单元

Phone: +86-21-62489820

Fax: +86-21-62489821 
(C) 2010 The Author(s). Licensee IntechOpen. This chapter is distributed under the terms of the Creative Commons Attribution-NonCommercialShareAlike-3.0 License, which permits use, distribution and reproduction for non-commercial purposes, provided the original is properly cited and derivative works building on this content are distributed under the same license. 